\title{
Research on the Economic Evaluation of Retirement Community of China Based on the System Dynamics
}

\author{
Ting $\mathrm{LI}^{1,}{ }^{*}$ and Feng $\mathrm{LAN}^{1}$ \\ ${ }^{1}$ Department of Management Xi'an University of Architecture \&Technology, Xi'an, \\ China
}

*Email:465431141@qq.com

Keywords: Retirement community, System dynamics, Economic evaluation.

\begin{abstract}
This paper reviewed retirement community concept, characteristics, meaning based on the economic evaluation, project planning and investment operating theory of real estate. Further, retirement community project's economic evaluation model was built by using system dynamics method. Then, this article implemented dynamic simulation and analyzed the effect of project operation and evaluate its economic feasibility. Results show that the government's policy, construction cost and the late management play important roles in retirement community project. In addition, the system dynamics has validity in economic evaluation of retirement community project. Simulation results can provide references for project investment decisions.
\end{abstract}

\section{Introduction}

By the end of 2014, aging population over 60 years old in China has reached 212 million that accounting for $15.5 \%$ of the total population, and the average annual growth rate is $3 \%$, our country is in the stage of rapid aging. China had issued the policies and regulations for supporting the development of pension business since the 12th five-year plan, developmental upsurge of endowment real estate has emerged. However, there are a lot of problems in the development of endowment property just as opportunities and challenges exist side by side. Outstanding performance in these problems is long investment cycle, large investment, high risk, financing difficulties, the single profit model, the lack of interdisciplinary talents in the cross field of real estate development and pension services, less successful cases, complex management in post operation, low market acceptance and so on.

This article is intended to explore the pension laws between the costs and benefits of retirement community development, expect to provide reference basis for investment decisions, enrich and perfect the related economical evaluation theory, and provide theoretical basis for real estate development under the background of aging population.

\section{The Related Researches and Perspective}

At present, the relevant research on the endowment real estate is earlier, in the field of retirement community, the research mainly involves the operating mode, the satisfaction of consumer, the government's policies and so on. For example, Thomas P.Williams (1985) studied the continuing care retirement community (CCRC), their studies have shown that as the more and more establishment of CCRC, market competition intensifies, feasibility study report and the reliability of the evaluation has important significance on the success or failure of project [2].John V. Valen (1989) argued that CCRC's operator is necessary to provide clear and transparent financial 
statements for residents on a regular basis, this requires operators to estimate of future costs and revenues on [3].Bram Verschuere (2012) discussed the differences of aged care facilities among the public sector, private non-profit organizations, private business and explained the aged care facilities operating condition under different supervision form [4].Han Kwee (2003) used the satisfaction of the elderly life as the breakthrough point, found the friendship in retirement community and affection in family endowment is the dominant factors affecting the satisfaction of the elderly life [5].Costa - the Font, etc(2013) studied the relationship between European housing environment and the satisfaction of housing in the elderly. The results show that the housing environment quality has important influence on satisfaction [6].

Chinese researches on retirement community started late compared with foreign countries and mainly focused on the development pattern, financing way, operation management and so on. Du Zhimin (2012) argued that capital raising and daily operation is the biggest obstacle of the retirement community development in China, put forward the idea on how to run the retirement community in the future [7]. $\mathrm{Wu}$ Xingjian (2011) analyzed Chinese existing endowment real estate development mode are, and put forward two kinds of profit model suitable to China's endowment real estate [8].Lui Hongjun (2013) found that the core problem of endowment real estate is how to balance relationship between the cost and service, and he also found that the management mode of professional separation can improve residents' happiness [9].

Existing research mainly focused on the development problems of retirement community and the importance of operation mode, rarely involves the analysis of income, cost and economic evaluation of retirement community.

This article attempts to study retirement community projects from the perspective of economic evaluation by building an economic evaluation system dynamics model of retirement community project, simulating the project profitability, performing Montecarlo sensitivity analysis, so as to provide a reference basis for project investment decision.

\section{The Feasibility of the System Dynamics Apply to Economic Evaluation of Retirement Community Project}

System Dynamics System Dynamics (SD) was established by Jay W. Forrester professor of Massachusetts institute of technology (MIT) in 1956, and developed into an independent discipline in the late 50s. System dynamics regard the whole system as a feedback system and use the systematic, whole, associated viewpoint to study the influence factor of sports system and pay attention to the interaction within the system. System dynamics has been widely spread throughout the world since its creation, in recent years, the system dynamics has been widely applied to medical and health care, business management, regional planning, and many other aspects [10].

At present, China mainly has two endowment patterns: the permanent endowment and the long-distance endowment, permanent endowment is divided into family endowment and retirement community. Retirement community is a type of pension service system which dedicates to the service of the elderly with various functions and closely integrated with the real estate. In addition, it provides the elderly residential buildings outside and the whole course of pension service model includes food and beverage service, medical service, transportation service, life care services, intermediary services and other aspects of service requirements. Retirement community project is a complicated system engineering that is mainly composed of commercial 
operation, capital operation, service operation and so on. And it needs to integrate the investment and financing, construction and development, operations management and so on. Traditional project evaluation method cannot analyses complex system, use the principle of system dynamics to conduct a comprehensive analysis and judge for project profitability, solvency and capital balance so that it provide project managers reference basis for strategic planning and risk management.

\section{Building Economic Evaluation System Dynamics Model}

While different retirement communities project exist some differences in operating mode, it exists in common in the economic evaluation system. Figure 1 is cause and effect diagram of retirement community project economic evaluation, through it we can understand the mutual influence, interaction relations within retirement community projects.

The paper uses the system dynamic languages to do a detailed description for the variable relation in the system, simulates the behavior of the system, builds a retirement community project economic evaluation system dynamics model. The whole system consists of total investment estimation subsystems, investment and financing subsystems, revenue and sales tax subsystems, profit distribution subsystems, rights and interests for capital investment subsystems and cash flow subsystems, balance and balance sheet of subsystems. These subsystems provide comprehensive description on the development and operation of retirement community projects.
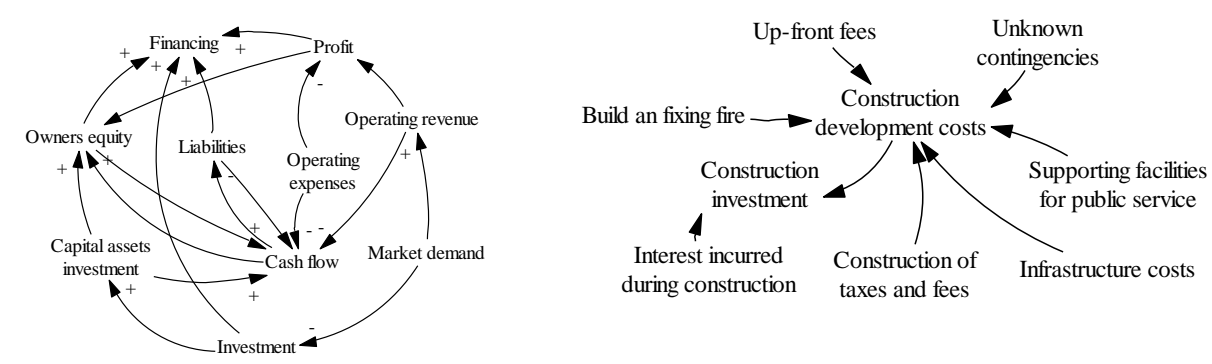

Figure 1: Causality diagram

Figure 2: Diagram of total investment estimation subsystem

\section{Total Investment Estimation of Subsystems}

Retirement community project's investment mainly includes pro-phase construction investment and late operating costs. In this article, the Work Breakdown Structure (WBS) method is used to establish the project investment cost framework and describe the internal Structure of investment estimation subsystem. Currently land cost of operating land retirement community project is higher because land's resources are generally state-owned land transfer. Retirement community project's construction and maintenance need a lot of money, and considering the demands of universality because the design emphasizes the basic design principles such as accessibility to increase the project cost, according to the survey retirement community project cost is a third higher than general commercial housing cost [12]. Retirement community project construction investment is mainly composed of construction of the construction period of development costs and development costs in figure 2.

\section{Investment and Financing Subsystem}

Retirement community project's have a strictly capital demand ,financing is the key to open the project, funding sources and repayment plan directly affects project cost of 
funding. Different sources and loan repayment way have large differences of the cost of capital. In figure 3, the cost of capital is made up of interest during construction and operation period.
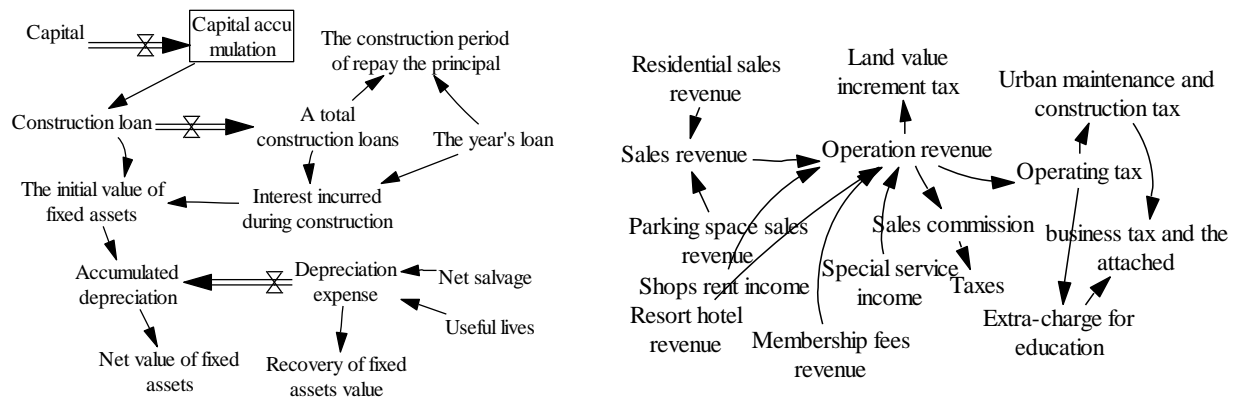

Figure 3: Investment and financing subsystems Figure 4: Operating income and sales tax subsystems

\section{Operating Income and Sales Taxes Subsystem}

The income constitutes of retirement community is complex, residential sales was part of the source of income, and provide persistent services, increase the added value of the community for the elderly is the main way to profit. The retirement community mainly have five basic profit models: sell, lease, rental simultaneously, "reverse mortgage" and membership, considering the pressure of funds, investors tend to choose several ways for effective combination to make project has stable cash flow. As shown in figure 4, the profitable pattern of retirement community includes sales, rental and membership.

\section{Profit Distribution Subsystem}

Profit distribution subsystem reflects the relationship of the total cost, revenue, profits in the project's calculation period and records the project process of the distribution of the profits. Figure 5 does not consider Non-operating income and non-business expenditure, so profit is actually operating profit.

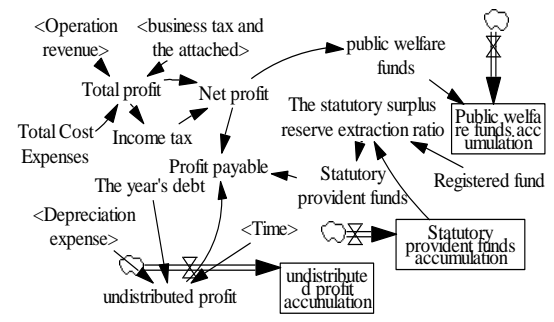

Figure 5: Profit distribution subsystem

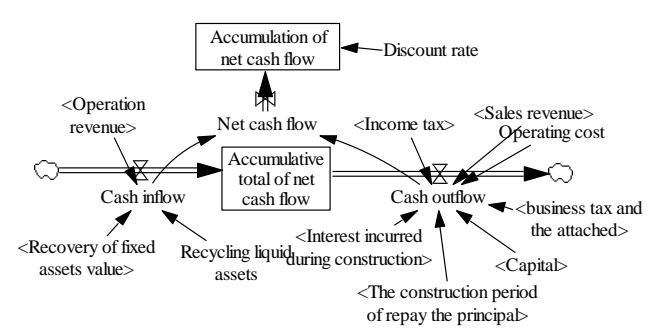

Figure 6: Equity capital investment subsystem

\section{Capital Investment Cash Flow Subsystem}

Cash flow subsystem recorded the process of project cash flow and cash flow. In investment analysis, project status of cash flow is more important than profit within a project. The success of a project depends on whether the cash can meet the payment during the project life. In figure 6 "net cash flow = cash inflow-cash outflow".

\section{Cash balance Subsystem}

Cash balance subsystem put all sources of funding as a cash inflow includes loans and capital investment from the perspective of fund balance and regards the profit distribution as a cash outflow, as shown in figure 7. 


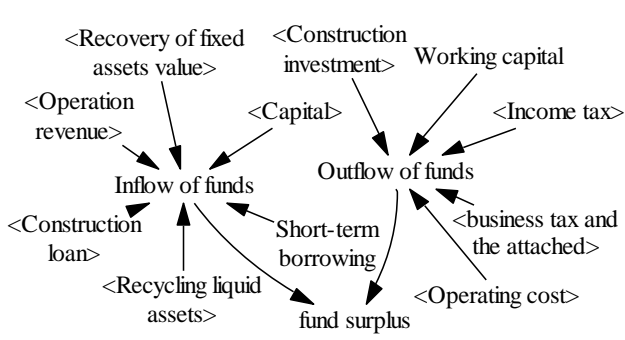

Figure 7: Profit distribution subsystem

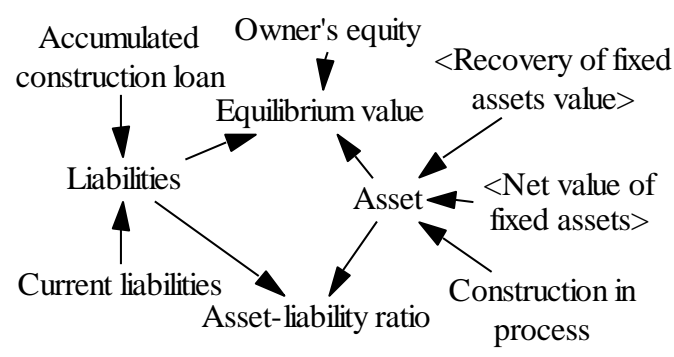

Figure 8: Assets and liabilities subsystem

\section{Assets and Liabilities Subsystem}

Assets and liabilities subsystem is used to test project's ability to repay the debt and resist financial risks. The difference between Assets and liabilities subsystem with other systems is that the assets and liabilities subsystem record the stock of variables and other systems is flow. Stock is the cumulative value of the variable at some point while flow is flow values of the variable at a particular moment. Figure 8 reflects the financial risk and the ability of debt paying of the project.

\section{Simulation}

\section{Project Overview}

YYY retirement community projects will put into use after completing construction within three years. The project covers an area of 90000 square meters, construction area of about 100000 square meters, Among them, the area of residential apartments for sale is about 72000 square meters, the area of business is about 1500 square meters, the area of food and beverage center is about 2500 square meters, the area of a health club is about 9000 square meters, the area of general hospital is about 10000 square meters, the area of resort hotel is about 9000 square meters. Inside the village form a complete set with the kindergarten, cultural activity center (university of old age, reading library), sports center (indoor: a goal kick, bowling, table tennis, etc; outdoor: basketball), etc. most of these facilities are located in the flat bottom and part of them open to the outside world. The integrated medical center of the project totally have 300 beds and signed an agreement with a first-class hospital, the first-class hospital will provide medical equipment and sent medical teams to management. Catering management will be conducted by professional catering, project investors only to participate in the turnover of project. Health club operates in the form of members. All shops in mall are only for rent.

\section{Simulation Assumptions}

This paper made the following assumptions in establishing YYY retirement community project economic evaluation simulation model:

(1)Assuming the project only have a single loan way, borrowing rates remain unchanged.

(2) The paper regardless of the project update, modification and maintenance cost during operation.

(3) Reimbursement means in construction period only pay interest of the project and begin reimbursement in project operating period, reimbursement deadline have 10 years. 
(4) Drawing lessons from the benchmark yield index of ordinary commodity housing market and considering the real profitability of retirement community projects, assuming that the benchmark yield of the objective was $10 \%$, the calculation period of the project is 50 years, the rate of the salvage value is $5 \%$ at the expiration of building.

(5) Assuming that the government gives certain discount in respect of the land.

(6)The value of model parameter was selected according to the investigation or simulation experiment method.

\section{Model Checking}

Subsystem in the balance sheet set "equilibrium value = assets - liabilities and owner's equity", the model found that equilibrium value always tends to zero through operating. Figure 9 illustrates the construction of the model is reasonable.
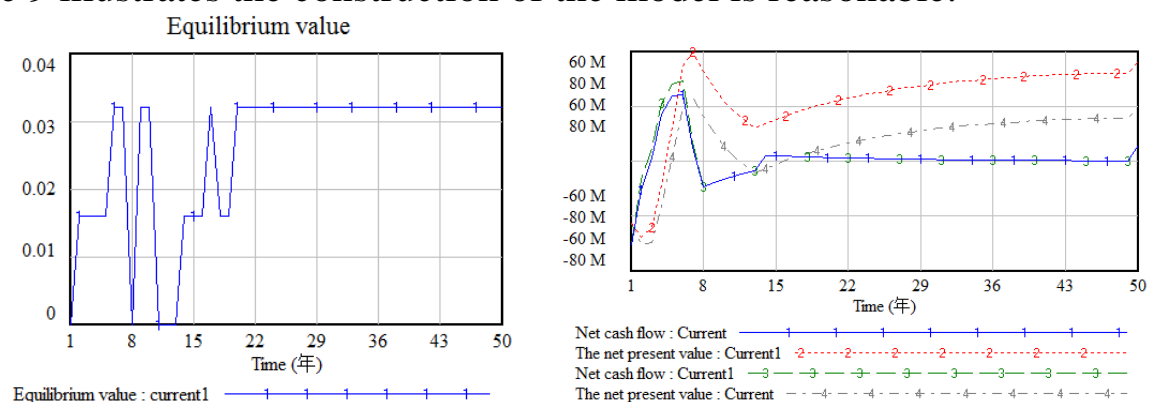

Figure 9: Diagram of equilibrium value Figure 10: Diagram of contrast analysis

\section{The results of Simulation}

Comparative Analysis. Model through operating can view a variable's value and analysis relationship between variable, simulate the effect of program when the values of parameters change. Figure 10 is the contrast figure of net present value when the residential selling price is between $6500 \mathrm{Yuan} / \mathrm{m} 2$ and $7500 \mathrm{Yuan} / \mathrm{m} 2$.

Montecarlo Sensitivity Analysis. In theory, the more the number of simulation, the more precise the result, the error of the simulation can be neglected. This paper took simulation 500 times. (1) Taking Montecarlo sensitivity analysis method to analysis the influence that residential sales price, parking space average selling prices, the average hotel occupancy rate to the cash flow. Changing interval of residential sales price is (6000 Yuan/m2, 10000 Yuan/m2), changing interval of average selling prices for parking spaces is from 60000 Yuan to 200000 Yuan, resort an average occupancy rate is from 0.5 to 0.95 , the number of membership is from 200 to 2000.Figure 11 shows the changes of net present value range is about -750 million Yuan to 600 million Yuan within the confidence interval of $(0.5,1)$.
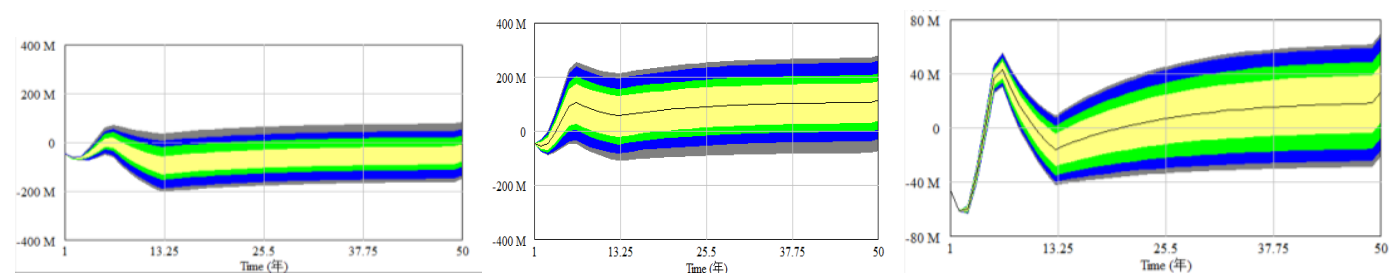

Figure 11: Sensitivity analysis diagram

(2) Taking Montecarlo sensitivity analysis method to analysis the influence that civil engineering, installation, construction and decoration engineering to the cash flow. Variable range for civil engineering construction cost from 950 Yuan $/ \mathrm{m} 2$ to 2000 Yuan/m2, variable range for project installation cost from $200 \mathrm{Yuan} / \mathrm{m} 2$ to 700 
Yuan/m2, variable range for decoration engineering cost from $300 \mathrm{Yuan} / \mathrm{m} 2$ to 1500 Yuan $/ \mathrm{m} 2$, and all of this is using random variation function. Figure 12 shows the changes of net present value range is about 20 million Yuan to 20 million Yuan Within the confidence interval of $(0.5,1)$.

(3) Taking Montecarlo sensitivity analysis method to analysis the influence that the number of management personnel, management personnel salary, other operating costs to the cash flow. The range of variable for management personnel number is from 20 to 100 , the range of variable for management personnel salary is from $2000 \mathrm{Yuan} / \mathrm{month}$ to 8000 Yuan/month, other variable range for operating costs is from 1 million Yuan/year to 10 million Yuan/square meters), and all of these are using random variation function. Figure 13 shows the changes of net present value range is about 20 million Yuan to 20 million Yuan Within the confidence interval of $(0.5,1)$.

\section{Summary}

Through the repeated simulation and quantitatively analysis evaluation indexes, and master the feasibility of the project development under the uncertainty change, simulation results show that the system dynamics method has promoted value to the retirement community project economic evaluation.

(1)The project is feasible from the project economic evaluation.YYY project conforms to national industrial policies and the development direction, project's positioning is accurate and development mode is reasonable, and it is helpful to promote the local economic construction and industrial development and expected to good response after being put into operation the market. The net present value of the objective is 40.1 million RMB, the investment internal rate of return is $18 \%$, and investment dynamic payback period is about 15 years. Therefore, this project has good economic and social benefits.

(2) Market acceptance of housing sales prices, sales of parking space, holiday hotel occupancy, costs of construction and installation and operation will affect the profit. So, there is a big risk in the project. At present endowment community projects mainly were dominated by real estate companies, but the real estate company is not good at operation management, it is necessary to outsourced later operations management to professional company through the way of service charge and issuing rewards and commission to raise the level of service management.

\section{Acknowledgement}

This research was financially supported by the Ministry of Housing and Urban-Rural Development in Shanxi (serial number:2015-R4-010) and Leading Academic Discipline Project of Xi'an University of Architecture \&Technology (serial number:XK201227).

\section{References}

[1] China's Population and Development Research Center of Research, Ma Li, Gui Jiangfeng. China's Ageing Population Strategy Research [J]. Economic Research Reference,2011,34:2-23.

[2] Williams T P, Rasmussen J A. Feasibility and Valuation of a Continuing Care Retirement Community[J]. Appraisal Journal, 1985. 
[3] Valorz, John V, Maribess Miller. Accounting For Continuing Care Retirement Communities [J]. Journal of Accountancy 168.3 (1989): 46-49.

[4] Verschuere B, Moray N, Decramer A. Commercial, Non-profit and Governmental Residential Elderly Care in Flanders: Differences in Client Selection and Efficiency? [J]. International Journal of Social Welfare, 2012, 21:384-392.

[5] Ho H K, Matsubayashi K, Wada T. What Determines the Life Satisfaction of the Elderly? Comparative Study of Residential Care Home and Community in Japan[J]. Geriatrics \& Gerontology International, 2003, 3:79-85.

[6] Costa-Font, Joan, Housing-related Well-being in Older People: The Impact of Environmental and Financial Influences [J]. Urban Studies,2013,50:657-673.

[7] Du Zhimin, Teng Meng. The Research on the Operational Mechanism and Development Prospects of Retirement Community of China [J]. Journal of Northwest University (Philosophy and Social Sciences Edition), 2012, 05:57-62.

[8] Wu Xinjian. Endowment real estate business model to explore [J]. Journal of urban development, 2011, 12:14-15.

[9] Lv hongjun, Li Menggang Wan Lijun. Urban Residents Endowment Real Estate Development Mode Study [J]. Journal of Learning and Exploration, 2013, 04:86-88.

[10]Chen Guowei jia-shan jin, jun-bao geng. System Dynamics Applied Research Review [J]. Journal of Control Engineering, 2012, 06:921-928.

[11]li Xianghua, Commercial Real Estate Project Economic Evaluation Model Based on SD Study [J]. Business Times, 2011, 33:123-124.

[12]Yang Chun, Cao Baoxin, Li Bing. An Aging Population and the Optimum Described Residential Design [J]. Journal of the Chinese Market, 2013, 32:55-57.

[13]Lan Feng, Liu Jia Community Nursing View of the Endowment Residence Value Chain And Value Creation Research [J].Mechanics and Materials.2013.02. 